\title{
Residual resource of power resistance during building structures deformation
}

\author{
Ekaterina Kuzina ${ }^{1, *}$, Vladimir Rimshin ${ }^{2}$, and Alexey Neverov ${ }^{1}$ \\ ${ }^{1}$ Research Institute of Building Physics of the Russian Academy of Architecture and Building \\ Sciences, 127238, 21, Locomotive passage, Moscow, Russia \\ ${ }^{2}$ Moscow State University of Civil Engineering (MGSU), 129337, 26, Yaroslavskoye Shosse, \\ Moscow, Russia
}

\begin{abstract}
Modern scientific research and design developments, based on the fundamental principles of physics, mechanics and thermodynamics, are developing in a phenomenological direction. This implementation is found both in traditional integrated models of reinforced concrete using the advantages of computer technology, and in discrete models following the grid methods of solid deformable body mechanics. Discrete models in content and chronology over time are hereditary with respect to integral models. The theoretical basis for calculating the residual life of the force resistance to deformation, determines the stiffness of the cross sections of reinforced concrete elements with a maximum bending moment and with zero bending moment are presented in this article.
\end{abstract}

\section{Introduction}

The logical basis of phenomenological methods is the experimental-statistical assessment of the factors and consequences of the deformation and destruction processes in materials and structures, the identification and analysis of existing quantitative and qualitative relationships between them, a results generalization, followed by the formulation of the hypotheses and invariants system necessary to create an applied theory and determine the structure when solving the problems of concrete and reinforced concrete power resistance. Concrete is characterized by anisotropy of force resistance. Its use in load-bearing structures is facilitated by compensatory reinforcement. The strength resistance of reinforced concrete is collectively determined by the properties of its components and the specifics of their joint work, including the adhesion of reinforcement to concrete. At the same time, the strength resistance of concrete, reinforcement, and adhesion between them are distinguished by the nonlinearity of the relationship between stresses and strains, creep, a certain irreversibility of strains, age wear; concrete responds to changes in the physicochemical and pyrometric characteristics of the medium, on the history and time conditions of loading and impacts [1-9].

*Corresponding author: kkuzzina@mail.ru 


\section{Materials and method}

Nonequilibrium problem statement actualizes the search for preferred specific forms of writing rheological equations of the materials mechanical state where time acts as a factor that determines the primacy of the functional-mode relationship between stresses, strains and time, and at the same time.

Real reinforced concrete structures, especially those of environmental protection, communication and communal use, have an increased risk degree of unacceptable damage caused by technogenic or biological aggressive effects (the effect is considered as corrosion damage). The problem of ensuring the state of fracture toughness (absence of cracks) for a specified period of time has the problem of predicting the moment of cracks occurrence in the stretched zones of reinforced concrete elements with the maximum in terms of quantity and significance factors of strength and corrosion content [10-18].

The basic rheological equation of the concrete force resistance has the form in the modern theory of reinforced concrete:

$$
\varepsilon\left(t, t_{0}\right)=\sigma(t) \cdot \frac{S_{M}^{0} \cdot[\sigma(t)]}{B_{M}^{0}(t)}+\sigma(t) \cdot S_{n}^{0} \cdot[\sigma(t)] \cdot C(t, t)-\int_{t_{0}}^{t} S_{n}^{0} \cdot[\sigma(t)] \cdot \sigma(t) \cdot \frac{\partial}{\partial \tau} \cdot C(t, \tau) \cdot d \tau
$$
$\left(t, t_{0}\right)$;

where $\varepsilon\left(t, t_{0}\right)$ - the total force relative deformation accumulated over a period of time

$\mathrm{S}_{\mathrm{M}}^{0} ; \mathrm{S}_{\mathrm{n}}^{0}-$ nonlinearity functions for instantaneous strains and for creep strains;

$$
\varepsilon_{M}(t)=\sigma(t) \cdot \frac{S_{M}^{0} \cdot[\sigma(t)]}{B_{M}^{0}(t)}
$$

where $\varepsilon_{M}(t)$ - instantaneous relative force deformation at time $t$;

$$
\varepsilon_{\mathrm{n}, c r}(\mathrm{t})=\sigma(\mathrm{t}) \cdot \mathrm{S}_{\mathrm{n}}^{0} \cdot[\sigma(\mathrm{t})] \cdot \mathrm{C}_{0}(\mathrm{t}, \mathrm{t})
$$

where $\varepsilon_{\mathrm{n} / \mathrm{cr}}(\mathrm{t})$ - short-term force relative creep strain at time $\mathrm{t}$;

$$
\varepsilon_{n}\left(t, t_{0}\right)=\int_{t_{0}}^{t} S_{n}^{0} \cdot[\sigma(t)] \cdot \sigma(t) \cdot \frac{\partial}{\partial \tau} \cdot C^{*}(t, \tau) \cdot d \tau
$$

where $\varepsilon_{n}\left(t, t_{0}\right)$ - the relative creep strain accumulated over the time interval $\left(t, t_{0}\right)$;

$t_{0}, t, \tau$ - reference point, current time, observation time;

$\sigma(\mathrm{t})$ - voltage acting at time instant $\tau$.

Nonlinearity functions have many recording options; the method uses the expressions introduced in [6].

$$
\begin{gathered}
\mathrm{S}^{0}=1+\mathrm{V} \cdot\left(\frac{\sigma}{\mathrm{R}}\right)^{2} \\
\mathrm{~V}_{\mathrm{m}}=\frac{37,5}{\mathrm{R}_{\mathrm{pr}}} \\
\mathrm{m}_{\mathrm{M}}=5.7-0.05 \cdot \mathrm{R}_{\mathrm{pr}} \\
\mathrm{V}_{\mathrm{m}}=\frac{45,0}{\mathrm{R}_{\mathrm{pr}}} \\
\mathrm{m}_{\mathrm{n}}=5.0-0.07 \cdot \mathrm{R}_{\mathrm{pr}}
\end{gathered}
$$

where $\mathrm{R}_{\mathrm{pr}}$ - prismatic strength, $\mathrm{MPa}$. 
Moreover, in the recommendations of the Concrete and Reinforced Concrete Research Institute formulas are presented in tabular form in table 1.

Table 1. Nonlinearity parameters according to the Concrete and Reinforced Concrete Research Institute recommendations.

\begin{tabular}{|c|c|c|c|c|c|c|c|}
\hline \multirow{2}{*}{$\begin{array}{c}\text { Nonlinearity } \\
\text { parameters }\end{array}$} & \multicolumn{6}{|c|}{ Numerical values of nonlinearity parameters for concrete classes B } \\
\cline { 2 - 8 } & 12,5 & 15 & 20 & 30 & 40 & 50 & 60 \\
\hline $\mathrm{V}_{\mathrm{m}}$ & 3,1 & 2,6 & 2,0 & 1,3 & 1,0 & 0,8 & 0,7 \\
\hline $\mathrm{m}_{\mathrm{M}}$ & 5,0 & 5,0 & 4,7 & 4,3 & 3,8 & 3,4 & 3,0 \\
\hline $\mathrm{V}_{\mathrm{n}}$ & 3,72 & 3,11 & 2,35 & 1,6 & 1,22 & 1,22 & 1,22 \\
\hline $\mathrm{m}_{\mathrm{n}}$ & \multicolumn{7}{|c|}{4,0} \\
\hline
\end{tabular}

In the interests of applied calculations and the use of the formula for multidimensional problems, a quasilinear equation [19-30] of the form is introduced as

$$
\varepsilon\left(t, t_{0}\right)=S^{0} \cdot[\sigma(t)] \cdot \frac{\sigma(t)}{E_{T}^{L}(t)}
$$

or

$$
\varepsilon\left(t, t_{0}\right)=S^{0} \cdot[\sigma(t)]\left\{\sigma(t)\left[\frac{1}{\varepsilon_{M}^{0}(t)}+C_{n}(t, t)-\int_{t_{0}}^{t} \frac{\sigma(\tau)}{\sigma(t)} \frac{\partial}{\partial \tau} C_{n}(t, \tau) d \tau\right]\right\}
$$

where

$$
\frac{1}{E_{t, L}\left(t, t_{0}\right)}=\frac{1}{E_{M}^{0}(t)}+C_{n}(t, t)-\int_{t_{0}}^{t} \frac{\sigma(\tau)}{\sigma(t)} \frac{\partial}{\partial \tau} C_{n}(t, \tau) d \tau
$$

$\mathrm{E}_{\mathrm{t}, \mathrm{L}}\left(\mathrm{t}, \mathrm{t}_{\mathrm{0}}\right)$ - linear temporary deformation modulus;

$S^{0} \cdot[\sigma(t)]$ - a single nonlinearity function calculated at time $t$ for which the parameter $\mathrm{V}$ is determined by the formula

$$
V=\frac{42,5}{R_{p r l l}}
$$

And $\mathrm{m}$ is taken $\mathrm{m}=4.0$.

Such a simplification provides at least $97 \%$ of the accuracy for the calculations [25-34]. It should be recalled that for $\sigma=$ const

$$
\begin{aligned}
& \frac{1}{E_{t, L}\left(t, t_{0}\right)}=\frac{1}{E_{M}^{0}(t)}+C_{n}(t, t) \\
& \varepsilon\left(t, t_{0}\right)=S^{0} \cdot[\sigma(t)] \frac{\sigma(t)}{E_{t, L}\left(t, t_{0}\right)}
\end{aligned}
$$

\section{Results and discussion}

The stiffness of reinforced concrete elements sections is determined relative to the axis passing through the gravity center of the reduced section, since the calculated stiffness value is the smallest. It should be noted that in the physically linear formulation of the problem, the desired center of gravity is located on the neutral axis of the section. 
Based on the condition that bending the stiffness of the damaged beam element relative to the gravity center of the section

$$
D^{*}=\sum_{K=1}^{n} A_{K} E_{K}^{*} r_{K}^{2}
$$

where $A_{K}$ - sectional area of the Kth component;

$\mathrm{E}_{\mathrm{K}}^{*}$ - temporary deformation modulus of component $\mathrm{K}$ at the level of its gravity center, taking into account damage;

$r_{K}$ - the distance between the gravity center of the reduced section and the gravity center of the Kth component, we write

$$
r_{K}=r_{V s e c}-r_{V, K}
$$

where

$$
r_{V, \sec }=\sum_{K=1}^{n} \frac{A_{K} \bar{E}_{K}^{-} r_{K}}{\sum_{i=1}^{n} A_{K} E_{K}^{*}}
$$

or

$$
\begin{gathered}
r_{V, 1}=\frac{5}{8} \delta \\
r_{H, V}=h_{0}-\left(Z^{*}+\delta+\frac{1}{2} \rho\right) \\
r_{S, V}=h_{0}-Z^{*}
\end{gathered}
$$

as well as

$$
E_{t, i}^{*}=E_{t, L_{i}}^{*} K\left(r_{V, i}\right)=\frac{E_{t, L} K\left(r_{V, i}\right)}{S^{v, 0}\left(r_{V, i}\right)}
$$

(here the damage function and the nonlinearity function are fixed at the level of the gravity center of the transition region). Then, taking into account the formula, we obtain

$$
\begin{array}{r}
K\left(r_{V 1}\right)=0,86 \\
S^{0}\left(r_{V 1}\right)=1+V
\end{array}
$$

That is

$$
E_{1, t}^{*}=\frac{0,86 \bar{E}_{t, l}\left(t, t_{0}\right)}{1+V}
$$

In addition, for intact zone $\mathrm{H}$

$$
E_{H, t}^{*}=\frac{E_{t, l}\left(t, t_{0}\right)}{1+V}
$$

and for tensile reinforcement, the strain modulus is $E_{\mathrm{S}}$.

Further

$$
\begin{aligned}
& r_{C . T_{.1}}=r_{V_{, s e C}}-r_{V_{0} 1} \\
& r_{C . T . H}=r_{V_{, s e C}}-r_{\mathrm{H}, 1}
\end{aligned}
$$




$$
r_{c, \mathrm{~T} S}=r_{V, \sec }-r_{S, V}
$$

and working areas of components

$$
\begin{gathered}
A_{1}=\frac{2}{a} b \delta \\
A_{H}=b \rho \\
\mathrm{A}_{S}=\omega_{S} A_{S 0}
\end{gathered}
$$

In this way,

a) the stiffness of the normal section with the maximum bending moment after substitution in the formula

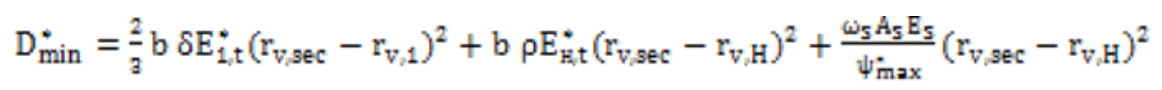

where $\psi^{*} \leq 1$ - is the coefficient of participation in the force resistance according to the stiffness of the undamaged concrete of the stretched zone (in the zone of the maximum moment $\psi^{*}=1$ );

b) the stiffness of the normal section with zero bending moment, with the maximum stiffness, is calculated in a linear setting relative to the neutral zone of the axis, taking into account the elimination of parts of the section due to corrosion damage

$$
\mathrm{D}_{\max }^{*}=\frac{2}{3} b \delta E_{t, L} r_{1}^{2}+b \rho E_{t, L} r_{H}^{2}++\frac{\omega_{s} A_{s} E_{s}}{\psi_{\min }}
$$

where

$$
\left.\begin{array}{c}
r_{1}=x-\frac{5}{8} \delta ; \\
r_{H}=\frac{1}{2} P ; \\
r_{S}=h_{0}-x .
\end{array}\right\}
$$

Intermediate stiffness values are calculated similarly, but sequential refinement procedures are required.

For practical use, it is permissible to use working approximate approximations

- for lateral bending

$$
\begin{gathered}
\frac{1}{D^{*}}=\frac{1}{D_{\max }^{*}}+\left(\frac{1}{D_{\min }^{*}}-\frac{1}{D_{\max }^{*}}\right) \frac{M}{M_{n p}^{*}} \\
D^{*}=\left[\frac{1}{D_{\max }^{*}}+\left(\frac{1}{D_{\min }^{*}}-\frac{1}{D_{\max }^{*}}\right) \frac{M}{M_{\text {np }}^{*}}\right]^{-1}
\end{gathered}
$$

-for eccentric compression

$$
D^{*}=D_{\max }^{*}\left[1-\left(1-\frac{D_{\min }}{D_{\max }}\right)\left(\frac{M}{M_{n p}^{*}}+\frac{p}{P_{n p}^{*}}\right)\right]\left(\frac{p_{n}}{P_{n p}^{*}}+\frac{M}{M_{n p}^{*}}\right)
$$

When $\frac{\mathrm{p}}{\mathrm{p}_{\mathrm{np}}^{\mathrm{p}}}+\frac{\mathrm{M}}{\mathrm{M}_{\mathrm{np}}^{*}} \leq 1$, moreover, at large moments, the compressive force is neglected, and at high compressive forces, the moment is neglected [35-36].

For example, for a single-span pivotally supported beam loaded with a uniform load $\mathrm{q}=$ const, when 


$$
M=\frac{q}{2} V(1-V)-\frac{q l V}{2}-\frac{q^{2}}{2} \text { и } \quad \frac{d^{2} u}{d x^{2}}=-\frac{M}{D^{*}}
$$

expression for the greatest deflection in the middle of the span

$$
\begin{gathered}
\mathrm{U}_{\max }=(1+\eta) \mathrm{U}_{\max }^{0} \\
\text { where } \mathrm{U}_{\max }^{0}=\frac{5}{384} \frac{\mathrm{ql^{2 }}}{\mathrm{D}_{\max }^{+}} ;(1+\eta)=1+\frac{11}{100} \frac{\mathrm{ql}^{2}}{\mathrm{M}_{\mathrm{n} p}^{-}}\left(\frac{D_{\max }^{*}}{D_{\min }^{*}}-1\right)>1
\end{gathered}
$$

\section{Conclusions}

The theoretical basis for calculating the residual life of the force resistance to deformation, determines the stiffness of the cross sections of reinforced concrete elements with a maximum bending moment and with zero bending moment are presented in this article. The sections stiffness of reinforced concrete elements is determined relative to the axis passing through the gravity center of the reduced section, since the calculated stiffness value is the smallest.

\section{References}

1. V. Telichenko, V. Rimshin, E. Kuzina, Methods for calculating the reinforcement of concrete slabs with carbon composite materials based on the finite element model. MATEC Web of Conf., 251, № 04061 (2018)

2. V. Telichenko, V. Rimshin, V. Eremeev, V. Kurbatov, Mathematical modeling of groundwaters pressure distribution in the underground structures by cylindrical form zon. MATEC Web of Conf., 196, № 02025 (2018)

3. A.A. Varlamov, V.I. Rimshin, S.Y. Tverskoi, The modulus of elasticity in the theory of degradation. IOP Conf. Series: Mat. Scien. and Eng., 463 (2), № 022029 (2018)

4. A.L. Krishan, V.I. Rimshin, M.A. Astafeva, Deformability of a Volume-Compressed Concrete. IOP Conf. Series: Mat. Sci. and Eng., 463 (2), № 022063, (2018)

5. A.A. Varlamov, V.I. Rimshin, S.Y. Tverskoi, The General theory of degradation. IOP Conf. Series: Mat. Sci. and Eng., 463 (2), № 022028 (2018)

6. A.L. Krishan, V.I. Rimshin, E.A. Troshkina, Strength of Short Concrete Filled Steel Tube columns of Annular Cross Section. IOP Conf. Series: Mat. Sci. and Eng., 463 (2), № 022062 (2018)

7. A.L. Krishan, M.Yu. Narkevich, A.I. Sagadatov, V.I. Rimshin, Experimental investigation of selection of warm mode for high-performance self-stressing selfcompacting concrete. IOP Conf. Series: Mat. Sci. and Eng., 456 (1), № 012049 (2018).

8. A.A. Varlamov, V.I. Rimshin, S.Y. Tverskoi, Planning and management of urban environment using the models of degradation theory. IOP Conf. Series: Earth and Envir. Sci., 177 (1), № 012040 (2018)

9. V.I. Rimshin, B.V. Labudin, V.I. Melekhov, A. Orlov, V.L. Kurbatov, Improvement of strength and stiffness of components of main struts with foundation in wooden frame buildings. ARPN J. of Eng. and Appl. Sci., 13 (11), pp. 3851-3856 (2018)

10. V.I. Rimshin, A.A. Varlamov, Three-dimensional model of elastic behavior of the composite (2018)

11. V.I. Rimshin, A.A. Pudova, L.I. Shubin, Evaluation of efficiency of use of photoelectric systems at operation of a residential house (2018) 
12. A.A. Varlamov, V.I. Rimshin, S.Y. Tverskoi, Security and destruction of technical systems. IFAC-PapersOnLine, 51 (30), pp. 808-811 (2018)

13. E. Kuzina, V. Rimshin, Deformation Monitoring of Road Transport Structures and Facilities Using Engineering and Geodetic Techniques. Ad. in Int. Syst. and Comp., 692, pp. 410-416 (2018)

14. E. Kuzina, A. Cherkas, Technical aspects of using composite materials for strengthening constructions. IOP Conference Series: Materials Science and Engineering, 365 (3), № 032053 (2018)

15. A. Cherkas, V. Rimshin, Application of composite reinforcement for modernization of buildings and structures. MATEC Web of Conf., 117, № 00027 (2017)

16. V., Rimshin, R., Aralov, Sustainable regeneration of urban areas (using the example of Moscow renovation program. E3S Web of Conf., 110, № 01011 (2019)

17. E. Kuzina, V. Rimshin, Experimental and calculated evaluation of carbon fiber reinforcing for increasing concrete columns carrying capacity. E3S Web of Conf., 97, № 04007 (2019)

18. E. Kuzina, V. Rimshin, Strengthening of Concrete Beams with the Use of Carbon Fiber. Ad. in Int. Syst. and Comp., 983, pp. 911-919 (2019)

19. A. Varlamov, V. Rimshin, S. Tverskoi, A method for assessing the stress-strain state of reinforced concrete structures. E3S Web of Conf., 91, № 02046 (2019)

20. V. Rimshin, B. Labudin, V. Morozov, A. Orlov, A. Kazarian, V. Kazaryan, Calculation of Shear Stability of Conjugation of the Main Pillars with the Foundation in Wooden Frame Buildings. Ad. in Int. Syst. and Comp., 983, pp. 867-876 (2019)

21. E. Kuzina, V. Rimshin, V. Kurbatov, The Reliability of Building Structures Against Power and Environmental Degradation Effects. IOP Conf. Series: Mat. Sci. and Eng., 463 (4), № 042009 (2018)

22. N.I. Karpenko, V.A. Eryshev, V.I. Rimshin, The Limiting Values of Moments and Deformations Ratio in Strength Calculations Using Specified Material Diagrams. IOP Conf. Series: Mat. Sci. and Eng., 463 (3), № 032024 (2018)

23. I.L. Shubin, Y.V. Zaitsev, V.I. Rimshin, V.L. Kurbatov, P.S. Sultygova. Fracture of high performance materials under multiaxial compression and thermal effect. Eng. Solid Mech., 5 (2), pp. 139-144 (2017)

24. S.A. Korotaev, V.I. Kalashnikov, V.I. Rimshin, I.V. Erofeeva, V.L. Kurbatov, The impact of mineral Aggregates on the thermal conductivity of cement composites. Ecol., Envir. and Conser., 22 (3), pp. 1159-1164 (2016)

25. A.L. Krishan, E.A. Troshkina, V.I. Rimshin, V.A. Rahmanov, V.L. Kurbatov, Loadbearing capacity of short concrete-filled steel tube columns of circular cross section. Res. J. of Pharm., Biol. and Chem. Sci., 7 (3), pp. 2518-2529 (2016)

26. V.T. Erofeev, E.V. Zavalishin, V.I. Rimshin, V.L. Kurbatov, M.B. Stepanovich, Frame composites based on soluble glass. Res. J. of Pharm., Biol. and Chem. Sci., 7 (3), pp. 2506-2517 (2016)

27. Y.M. Bazhenov, V.T. Erofeev, V.I. Rimshin, S.V. Markov, V.L. Kurbatov, Changes in the topology of a concrete porous space in interactions with the external medium. Eng. Solid Mech., 4 (4), pp. 219-225 (2016)

28. V. Erofeev, V. Kalashnikov, S. Karpushin, A. Rodin, V. Smirnov, O. Smirnova, M. Moroz, V. Rimshin, I. Tretiakov, A. Matvievskiy, Physical and mechanical properties of the cement stone based on biocidal Portland cement with active mineral additive. Solid State Phen., 871, pp. 28-32 (2016) 
29. A. Krishan, V. Rimshin, V. Erofeev, V. Kurbatov, S. Markov, The energy integrity resistance to the destruction of the long-term strength concrete. Proc. Eng., 117 (1), pp. 211-217 (2015)

30. V.D. Antoshkin, V.I. Travush, V.T. Erofeev, V.I. Rimshin, V.L. Kurbatov, The problem optimization triangular geometric line field. Mod. Appl. Sci., 9 (3), pp. 46-50 (2015)

31. V.T. Erofeev, A.D. Bogatov, V.F. Smirnov, S.N. Bogatova, V.I. Rimshin, V.L. Kurbatov, Bioresistant building composites on the basis of glass wastes. Biosci. Biotech. Res. Asia, 12 (1), pp. 661-669 (2015)

32. V.M. Bondarenko, A.M. Kurzanov, V.I. Rimshin, The mechanism of seismic destruction of buildings (2000)

33. V.I. Rimshin, E.A. Larionov, V.T. Erofeyev, V.L. Kurbatov, Vibrocreep of concrete with a nonuniform stress state. Life Sci. J., 11 (11), pp. 278-280 ( 2014)

34. V.I. Telichenko, V.I. Rimshin, A.V. Karelskii, B.V. Labudin, V.L. Kurbatov, Strengthening technology of timber trusses by patch plates with toothed-plate connectors. J. of Ind. Poll. Cont., 33 (1), pp. 1034-1041 (2017)

35. A.L. Krishan, V.L. Rimshin, V.A. Rakhmanov, E.A. Troshkina, V.E. Kurbatov, Bearing capacity of short concrete filled steel tube columns of circular cross-section (2017)

36. A.L. Krishan, V.I. Rimshin, V.I. Telichenko, V.A. Rakhmanov, M.Yu. Narkevich, Practical implementation of the calculation of the bearing capacity trumpet-concrete column (2017) 